\title{
Adult mice cloned from migrating primordial germ cells
}

\author{
Yukiko Yamazaki*, Eleanor W. Low ${ }^{*}$, Yusuke Marikawa ${ }^{*}$, Kazuhiro Iwahashi ${ }^{*}$, Marisa S. \\ Bartolomei* $^{* *}$, John R. McCarrey ${ }^{* * *}$, Ryuzo Yanagimachi* \\ *Institute for Biogenesis Research, John A. Burns School of Medicine, University of Hawaii, \\ Honolulu, HI 96822; ** Howard Hughes Medical Institute and Department of Cell and Developmental \\ Biology, University of Pennsylvania School of Medicine, Philadelphia, PA 19104 \\ *** Department of Biology, University of Texas, San Antonio, TX 78249
}

Primordial germ cells (PGCs) undergo epigenetic modifications as they develop. It is known that pronounced epigenetic modifications commence with the entry of PGCs into the genital ridges [1]. Rapid and possibly active genome-wide demethylation in both male and female PGCs results in the erasure of imprints [2]. To examine the developmental potential of fetal germ cells, we used the nuclear transfer technique. When nuclei of germ cells at 10.5- to 19.5 -days-postcoitum (dpc) were used for cloning, 35-90\% of reconstructed oocytes developed to the 2-cell stage. After embryo transfer to surrogate mothers, we examined cloned fetuses in the mid-gestation stage. Fetuses cloned from $10.5 \mathrm{dpc}$ PGCs were morphologically normal (Figs. 1 and 2). In contrast, fetuses cloned from the germ cells at later stages $(11.5-19.5 \mathrm{dpc})$ were developmentally delayed in the mid-gestation stage (Figs. 1 and 2). The methylation status of the H19- and Snrpn-imprinting control regions (ICRs) in germ cell clones was similar to that of donor cells. We found that erasure of allele-specific methylation differences was already initiated in PGCs at $10.5 \mathrm{dpc}$ and was complete by $13.5 \mathrm{dpc}$. None of the embryos cloned from PGCs at 11.5 dpc or later survived to birth [3].

When nuclei of PGCs at 8.5, 9.5 and $10.5 \mathrm{dpc}$ were injected into enucleated oocytes, 35-40\% of reconstructed oocytes developed to the 2-cell stage (Table 1). Seven cloned 2-cell embryos developed into full-term offspring (Table 1). Of these, five, all derived from either 8.5 or $9.5 \mathrm{dpc}$ PGCs, developed into healthy adults with normal fertility. Two cloned offspring were also obtained from 10.5 dpc PGCs. One died shortly after birth and the other showed slight growth retardation at weaning although it subsequently developed into a fertile adult. To determine whether migrating PGCs possess normal genomic imprinting, we examined the allele-specific methylation pattern of the H19-and Snrpn-ICRs in PGCs at 9.5, 10.5 and 11.5 dpc. While the initiation of demethylation was evident at $9.5 \mathrm{dpc}$, most PGCs at this stage still maintained intact differential methylation pattern. Although erasure of the allele-specific methylation was more evident in PGCs at $10.5 \mathrm{dpc}$, more than half of the imprinted loci retained allele-specific methylation patterns. By $11.5 \mathrm{dpc}$, however, the majority of PGCs have completed the erasure of the allele-specific methylation in both the H19- and Snrpn-ICRs. Somatic cells of mice cloned from PGCs had normal methylated and unmethylated alleles at imprinted loci (Fig. 3). We conclude that PGCs at the early stages of development (until $10.5 \mathrm{dpc}$ ) retain intact genomic imprinting, and their nuclei are developmentally totipotent. Those at more advanced stages undergo progressive erasure of allele-specific differences in methylation at imprinted loci and therefore lose developmental totipotency.

[1] J.V. Schmidt et al., Genes Dev. 15(2000) 1997.

[2] M.A. Surani, Nature 414 (2001) 122.

[3] Y. Yamazaki et al., Proc. Natl. Acad. Sci. USA 100 (2003) 12207.

[4] This work was supported by National Institutes of Health Grant HD042772. 


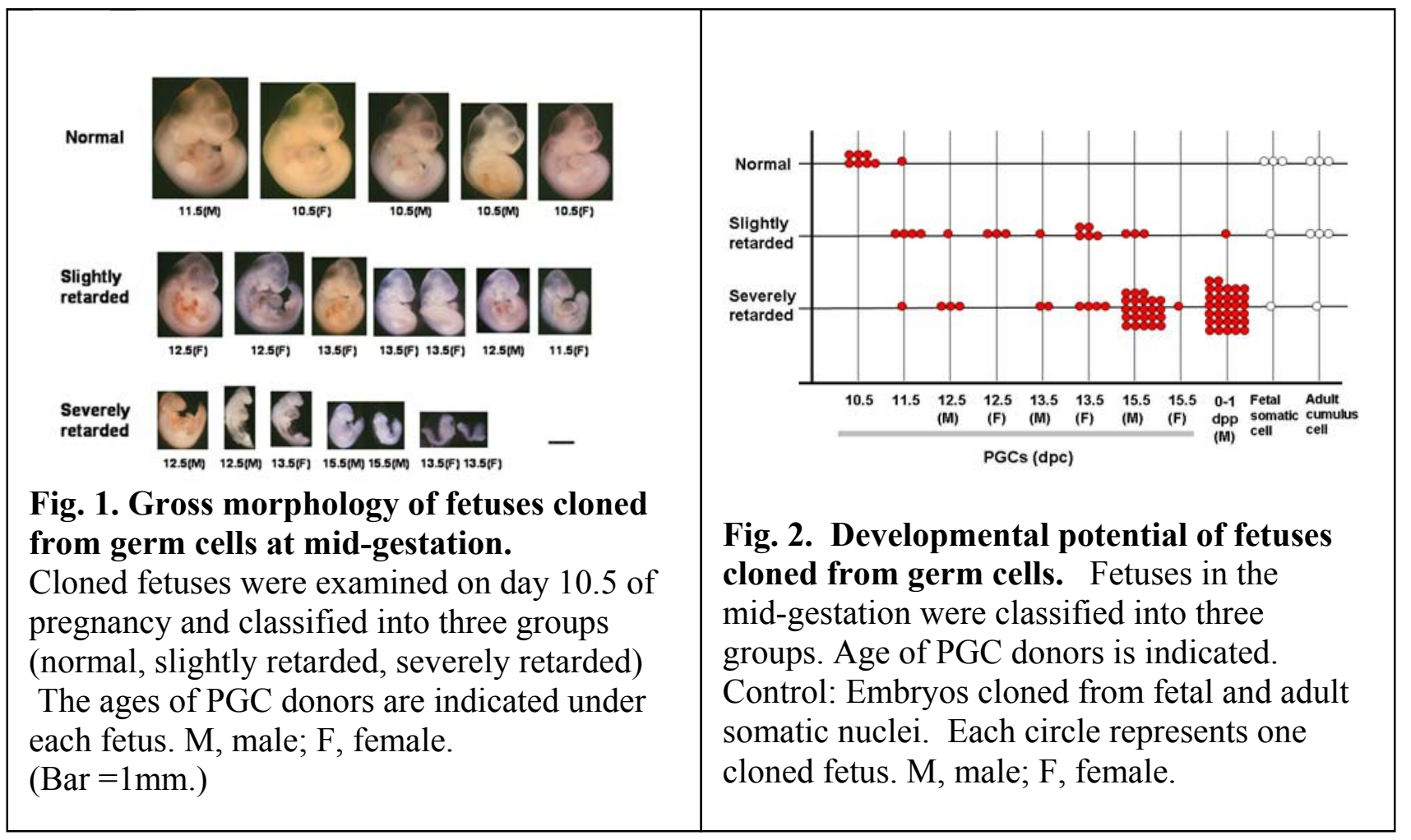

Table 1. Generation of pups cloned from PGCs at 8.5 -10.5 dpc

\begin{tabular}{|l|c|c|c|c|c|c|}
\hline PGC donors & $\begin{array}{c}\text { Age of } \\
\text { PGCs } \\
(\mathrm{dpc})\end{array}$ & $\begin{array}{c}\text { No. of } \\
\text { reconstructed } \\
\text { oocytes }\end{array}$ & $\begin{array}{c}\text { No. of } \\
\text { activated } \\
\text { oocytes }\end{array}$ & $\begin{array}{c}\text { No. of } \\
\text { 2-cell } \\
\text { embryos (\%) }\end{array}$ & $\begin{array}{c}\text { Full-term } \\
\text { pups (\%) }\end{array}$ & $\begin{array}{c}\text { Pups } \\
\text { survived }\end{array}$ \\
\hline OG2 x DBA & 8.5 & 144 & 137 & $50(36.5)$ & $1(2.0)$ & 1 \\
CD-1 x OG2 & 8.5 & 162 & 153 & $67(43.8)$ & $1(1.5)$ & 1 \\
OG2x DBA & 9.5 & 191 & 178 & $66(37.1)$ & $3(4.5)$ & 3 \\
OG2 x DBA & 10.5 & 351 & 338 & $149(44.1)$ & $2(1.3)$ & 1 \\
\hline
\end{tabular}

\begin{tabular}{|c|c|c|}
\hline $\begin{array}{l}\text { OG74-1F } \\
(10.5 \mathrm{dpc})\end{array}$ & 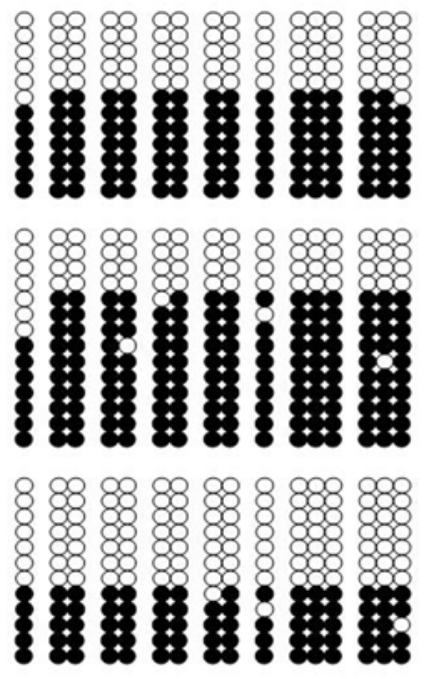 & $\begin{array}{l}\text { Fig. 3. Methylation status of the } \mathbf{H 1 9} \\
\text { DMD in mice cloned from } 9.5 \text { and } 10.5 \\
\text { dpc PGCs. } \\
\text { Genomic DNA was collected from tails of } \\
\text { two adult cloned mice- one cloned from } \\
\text { a } 9.5 \mathrm{dpc} \text { PGC (OG70-1F) and one cloned } \\
\text { from a } 10.5 \mathrm{dpc} \text { PGC (OG74-1F), and from } \\
\text { skin of a dead pup cloned from a } 10.5 \mathrm{dpc} \\
\text { PGC (OG77-1F), and analyzed for } \\
\text { methylation. All clones showed somatic } \\
\text { methylation pattern. One white circle } \\
\text { represents one unmethylated cytosine and } \\
\text { one black circle represents one methylated } \\
\text { cytosine. }\end{array}$ \\
\hline
\end{tabular}

